\title{
Differential contribution of right and left temporo-occipital and anterior temporal lesions to face recognition disorders
}

\section{Guido Gainotti* and Camillo Marra}

Department of Neuroscience, Neuropsychology Service, Università Cattolica di Roma, Rome, Italy

\section{Edited by:}

Hauke R. Heekeren, Max Planck Institute for Human Development, Germany

\section{Reviewed by:}

Oliver C. Schultheiss, Friedrich

Alexander University, Germany

Shozo Tobimatsu, Kyushu University,

Japan

\section{${ }^{*}$ Correspondence:}

Guido Gainotti, Center for

Neuropsychological Research,

Department of Neurosciences,

Policlinico Gemelli, Catholic University

of Rome, Largo A. Gemelli, 8, 00168

Roma, Italy.

e-mail: gainotti@rm.unicatt.it
In the study of prosopagnosia, several issues (such as the specific or non-specific manifestations of prosopagnosia, the unitary or non-unitary nature of this syndrome and the mechanisms underlying face recognition disorders) are still controversial. Two main sources of variance partially accounting for these controversies could be the qualitative differences between the face recognition disorders observed in patients with prevalent lesions of the right or left hemisphere and in those with lesions encroaching upon the temporo-occipital (TO) or the (right) anterior temporal cortex. Results of our review seem to confirm these suggestions. Indeed, they show that (a) the most specific forms of prosopagnosia are due to lesions of a right posterior network including the occipital face area and the fusiform face area, whereas (b) the face identification defects observed in patients with leftTO lesions seem due to a semantic defect impeding access to person-specific semantic information from the visual modality. Furthermore, face recognition defects resulting from right anterior temporal lesions can usually be considered as part of a multimodal people recognition disorder. The implications of our review are, therefore, the following: (1) to consider the components of visual agnosia often observed in prosopagnosic patients with bilateralTO lesions as part of a semantic defect, resulting from left-sided lesions (and not from prosopagnosia proper); (2) to systematically investigate voice recognition disorders in patients with right anterior temporal lesions to determine whether the face recognition defect should be considered a form of "associative prosopagnosia" or a form of the "multimodal people recognition disorder."

Keywords: prosopagnosia, multimodal people recognition disorders, unilateral lesions, visual object agnosia, familiarity feelings, configurational processing

\section{INTRODUCTION}

Selective analysis of faces is certainly the most powerful channel we have for recognizing familiar people and deriving important information about known or unknown persons, such as their emotional state, age, race, and gender. This is why the term "prosopagnosia," which was considered a form of visual agnosia specifically affecting face recognition, has played such a dominant role in the study of defective recognition and identification of familiar people since Bodamer's (1947) description of the defect. Nevertheless, although many studies that have tried to clarify the nature and mechanisms of acquired prosopagnosia, as well as its neuroanatomical underpinnings, many issues are still unresolved, including (a) the specific or non-specific manifestations of prosopagnosia; (b) the unitary or non-unitary nature of the disorder; and (c) the mechanisms underlying famous faces recognition disorders.

(a) Regarding the first point, some authors (e.g., Lhermitte et al., 1972; Damasio et al., 1982, 1990; Dixon et al., 1998; Gauthier et al., 1999a; Delvenne et al., 2004) have claimed that acquired prosopagnosia corresponds to a defect not only in recognizing familiar faces, but also in recognizing/discriminating among members of visually homogeneous categories. However, other authors (e.g., De Renzi, 1986a; Sergent and Signoret, 1992; McNeil and Warrington, 1993; Farah et al., 1995a; Rossion et al., 2003; Schiltz and Rossion, 2006;
Busigny et al., 2010a) hold that prosopagnosia cannot be related to general difficulty in discriminating visually similar exemplars of face and non-face categories.

(b) Regarding the second point, the debate revolves around De Renzi et al.'s (1991) proposal of distinguishing an "apperceptive" from an "associative" form of prosopagnosia, extending to selective face recognition disorders the classical Lissauer's (1890) distinction between an "apperceptive" and an "associative" form of visual agnosia. According to this distinction, in apperceptive agnosias recognition fails because of a subtle defect in visual perception, whereas in associative agnosias an intact visual percept cannot be associated with data stored in memory or deriving from other perceptual modalities. De Renzi et al. (1991) applied this basic distinction to face recognition, translated it into operational terms and proposed classifying as "apperceptive" the face recognition disorders of patients who, in addition to being unable to recognize familiar faces, also had problems in treating unknown faces, and as "associative" those in which no problem was found in the treatment of unfamiliar faces. Results obtained on Benton and Van Allen's (1968) unfamiliar matching tests (Benton Face Recognition Test, BFRT) are usually considered to provide the most reliable discrimination between apperceptive and associative forms of prosopagnosia; however, some authors (e.g., Benton, 1990; Davidoff and Landis, 1990; Farah, 1990; 
Sergent and Signoret, 1992; Duchaine and Weidenfeld, 2003; Duchaine and Nakayama, 2006) have argued that this test cannot be considered a good marker of the perceptual abilities involved in unfamiliar face recognition. Therefore, the distinction between "apperceptive" and "associative" forms of prosopagnosia and the most appropriate way to make this distinction are still quite controversial.

(c) Regarding the problem of the mechanisms underlying face recognition disorders, most authors agree that prosopagnosia is due to a defect in the holistic/configurational processing of faces (Yin, 1969; Sergent and Signoret, 1992; Kanwisher, 2000; Busigny et al., 2010b). But it is not clear whether this holistic process specifically concerns human faces, because of evolutionary determined innate factors, or whether it results from the acquisition of a high degree of expertise in the treatment of different classes of complex visual stimuli (Gauthier and Tarr, 1997; Gauthier et al., 1999b; Kanwisher, 2000; Gauthier and Nelson, 2001). If this were true, the holistic processing of faces would be at least partially due to the fact that faces are the visual stimuli most intensively and frequently processed by humans.

The difficulty of answering all of these questions is increased because prosopagnosia can be provoked by lesions in various parts of a bilateral network of cortical areas spanning from the inferior occipital areas [occipital face area (OFA) of Gauthier et al., 2000] to the anterior temporal cortex, with its center in the lateral portion of the mid-fusiform gyrus where the fusiform face area (FFA; Kanwisher et al., 1997) is located. Even though it is generally acknowledged that the inferior occipital areas mainly subsume the first stages of face perception and that the anterior temporal structures integrate information concerning the face, voice, and name of a familiar person, the exact functions of these different structures are only partially understood. Equally controversial is the role of disconnection mechanisms (Fox et al., 2008) or topdown processes (which allow obtaining performances that could not be obtained on the basis of simple bottom-up mechanisms) in this network (Etcoff et al., 1991; De Renzi and di Pellegrino, 1998; Barton and Cherkasova, 2003).

We believe that two main sources of variance at least partially account for these controversies. The first concerns the hemispheric side of the lesion in patients with posterior temporo-occipital (TO) injuries. In patients with left TO lesions, face recognition disorders can be part of a general visual recognition defect (or "visual object agnosia") in which the ability to access conceptual and personspecific semantic information from the visual modality is impaired; instead, in patients with right TO lesions the visual recognition disorder selectively concerns faces and seems due to a defect of a specific (configurational) form of visual processing.

Because both forms of visual agnosia can coexist in patients with bilateral lesions, there is the risk of attributing visual recognition disorders due to the concomitant left TO lesion to the mechanism responsible for prosopagnosia.

The second source of variance concerns the intrahemispheric locus of lesion and the nature of the people recognition defect in patients with right hemisphere damage. In fact, if disorders are circumscribed to the visual modality in patients with lesions encroaching upon the TO areas of this hemisphere, in those with lesions involving the right anterior temporal structures, people recognition disorders are multimodal, because they consistently affect familiar faces, voices, and names (see Gainotti, 2007a for a recent review). But, as these patients are often only aware of their difficulty in recognizing people by their faces and not of a similar defect for voices (Gainotti, 2010) and as the attention of students of prosopagnosia is often focused on subtle visual defects (sometimes neglecting the presence of similar defects in other modalities), the risk of incorrectly diagnosing prosopagnosic patients who have a multimodal person recognition disorder must be acknowledged.

\section{THE MAIN DIFFERENCES BETWEEN FACE RECOGNITION DISORDERS RESULTING FROM LEFT AND RIGHT TO LESIONS}

There are several important differences between "prosopagnosia" proper, resulting from right TO lesions, and the face recognition disorders that are sometimes observed in a context of "visual object agnosia" in patients with left TO damage. On one hand, these differences concern the impact of associative or semantic disturbances on the pathophysiology of visual recognition disorders resulting from left and right TO lesions and, on the other hand, the mode of stimulus processing disrupted in patients with left and right TO lesions. Regarding the first point, several authors (e.g., McCarthy and Warrington, 1986; De Renzi et al., 1987b; Damasio et al., 1988; De Renzi, 2000) have exhaustively demonstrated that visual recognition disorders resulting from left TO lesions are mainly due to associative or semantic disturbances and usually spare (but can sometimes include) face recognition. Regarding the second point, it is usually claimed that in left brain-damaged patients the defect mainly concerns analytical feature-based processing (Peretz, 1990; Bever and Chiarello, 2009), whereas in right brain-damaged patients the lesion disrupts a more holistic, configurational process operating on the spatial relationships among the face components (Sergent and Signoret, 1992; Kanwisher, 2000; Busigny et al., 2010b).

A final difference between the recognition disorders observed in patients with left and right TO lesions is that, due to the social relevance of distinguishing well known from unfamiliar people, an early step in the recognition of a known person concerns the emergence of familiarity feelings. These feelings are usually absent or very mild in the process of object recognition (with the possible exception of personal owning), but contribute in the process of person recognition by focusing attention on known faces and gathering additional, confirmatory information about them (Atkinson and Juola, 1974). Therefore, in the present review we will take into account each of these points and will try to disentangle their individual contributions to controversies concerning prosopagnosia.

\section{VISUAL RECOGNITION DISORDERS DUE TO GENERAL SEMANTIC DEFECTS OR SELECTIVELY AFFECTING FACES IN PATIENTS WITH LEFT AND RIGHT TO LESIONS}

Several pioneering authors (e.g., Albert et al., 1975; Pillon et al., 1981; Ferro and Santos, 1984; McCarthy and Warrington, 1986; Feinberg et al., 1994) showed that the recognition of familiar faces is often spared in patients with visual object agnosia provoked by unilateral left TO lesions. Results of investigations that have confirmed this clinical impression are reported in Table 1, in which each patient's reference authors, lesion anatomy, and clinical symptomatology are summarized. 
Table 1 | Patients with unilateral left temporo-occipital lesions who show visual object agnosia with spared recognition of faces.

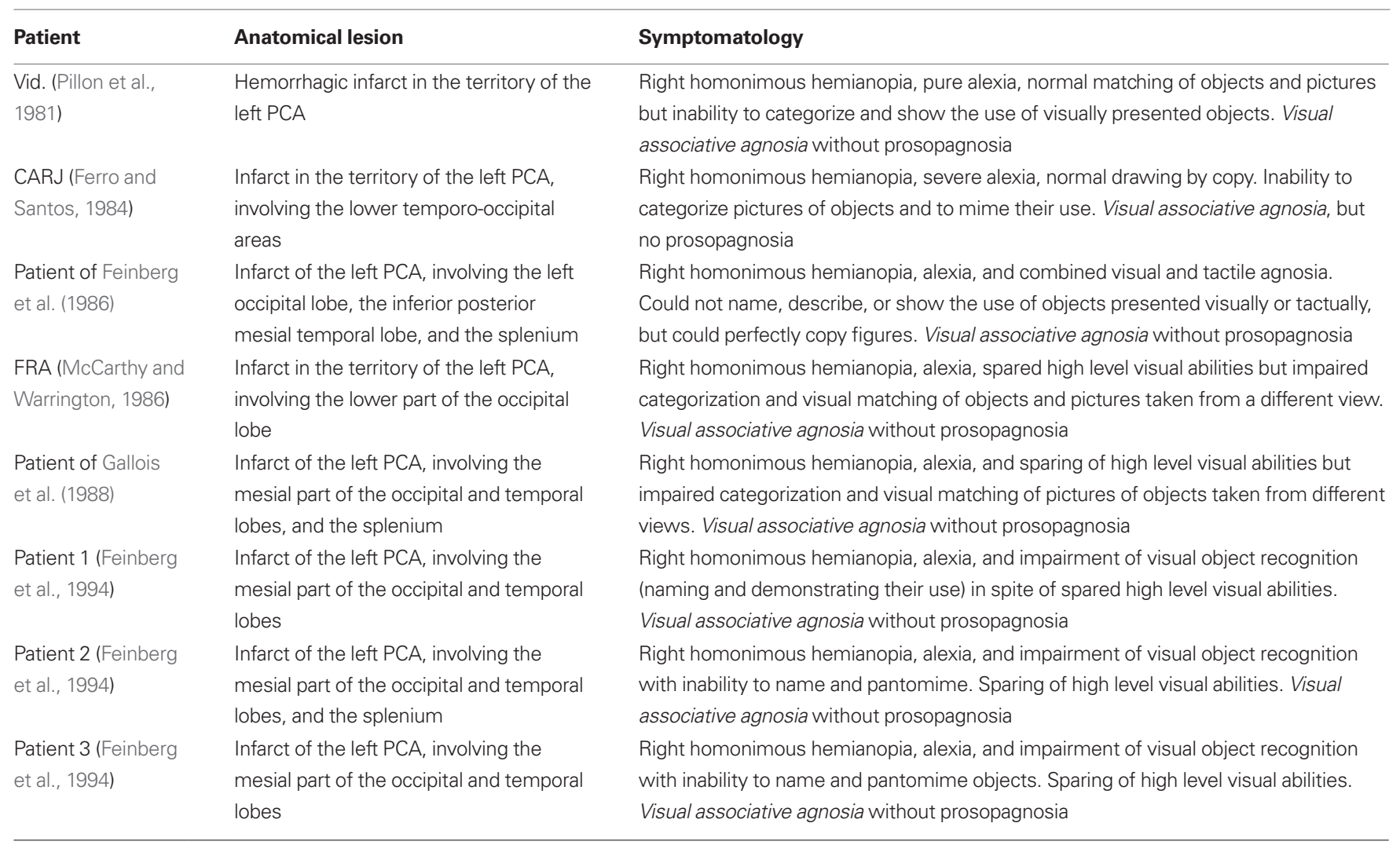

The data reported in Table 1 are clear, homogeneous, and consistent from both clinical and neuropathological viewpoints. All patients showed complete right homonymous hemianopia and were unable to name visually presented objects, which contrasted with their spared ability to name the same objects upon verbal definition or (less systematically) after tactile exploration. Furthermore, they were unable to pantomime the use of seen objects, categorize pictures, or match different pictures of the same object, but were able to copy figures and match identical versions of the same picture. Although they easily recognized familiar people, they were not always able to give their names because of their inability to name visual stimuli.

From a neuropathological point of view, all of these patients had suffered an infarct in the territory of the left posterior cerebral artery (PCA), which involved the inferior and mesial parts of the occipital and temporal lobes and, in some cases, the splenium of the corpus callosum.

These findings were also confirmed by results of systematic investigations (e.g., De Renzi et al., 1987b), which showed that patients with a left PCA infarct often have associative visual object agnosia with alexia but without prosopagnosia. There are, however, some exceptions to this rule. In fact, an association between prosopagnosia (with or without visual object agnosia) and left TO lesions has been observed in a limited number of patients. The data of these patients are reported in Table 2; they include reference authors, lesion anatomy, clinical symptomatology, presence of familiarity feelings and, when reported, type (configurational/holistic or based on a feature-by-feature analysis) of face processing.
Three main observations can be made from the data presented in Table 2: (1) First, a high proportion of the few left braindamaged patients with a face recognition (or identification) defect reported in the literature were left-handed. This was the case for patients AC and DN, reported respectively by Tzavaras et al. (1973) and Mattson et al. (2000) and for patient 015 reported by Barton (2008). (2) Second, with the exception of patient DN (Mattson et al., 2000), who had very low visual acuity, familiarity feelings were relatively or completely spared in these patients. This is surprising, because [as rightly stressed by Gross and Sergent (1992), and acknowledged by almost all authors] inability to experience a feeling of familiarity when viewing known faces is a hallmark of prosopagnosia. (3) Third, the observation that in patients with left TO lesions face recognition disorders often coexist with severe signs of visual object agnosia suggests (in agreement with Damasio et al.'s (1988) construct of "deep prosopagnosia") that these recognition disorders are part of a general inability to access conceptual and person-specific semantic information from the visual modality. Very few authors have analyzed the type of face processing used by their patients and in these cases the configurational processing defect seems less frequent than the feature analysis defect.

On the other hand, since the advent of neuroimaging, several studies have shown that when prosopagnosia is due to unilateral lesions these lesions usually encroach upon the right TO areas. Therefore, in Table 3 we tried to summarize the characteristics of the prosopagnosic patients we found in the literature with a lesion restricted to the right hemisphere; for each patient, we summarized 
Table 2 | Patients we found in the neuropsychological literature with face recognition disorders resulting from left temporo-occipital lesions.

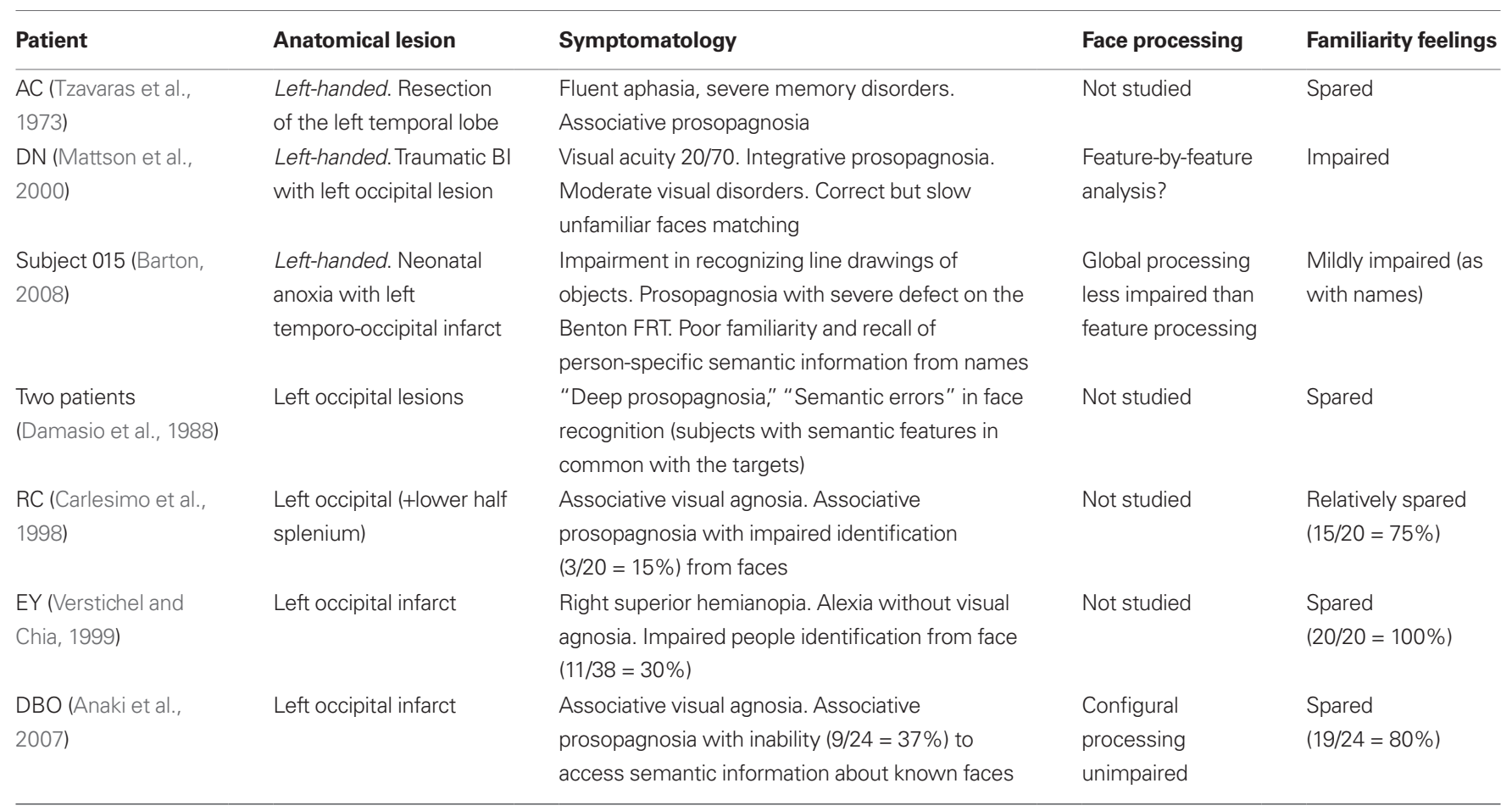

Bl, brain injury; FRT, Face Recognition Test.

the same data reported in Table 2, to characterize patients with face recognition or identification disorders resulting from left TO lesions.

The data reported in Table 3 allow us to make several observations. First, contrary to what happens in patients with face recognition disorders resulting from left TO lesions, face familiarity feelings are more or less severely impaired in all right prosopagnosic patients. This defect usually consists of a lack of subjective feelings alerting the patient that he is looking at a friend or a family member, but sometimes also includes the tendency to feel the faces of familiar people as "stranger" (Michel et al., 1986; Wada and Yamamoto, 2001; Uttner et al., 2002) or the tendency to feel well known and unknown faces as equally familiar (e.g., Barton et al., 2001, 2002). The second observation is that, when face processing is studied with methods that allow distinguishing global configurational encoding from local feature-by-feature analysis, a defective configurational process is observed in most patients. The severity of this defective configurational process can, however, vary from patient to patient. For instance, it was very clear in patients LH (Levine and Calvanio, 1989; Etcoff et al., 1991; Farah et al., 1995b), BM (Sergent and Villemure, 1989), PM and RM (Sergent and Signoret, 1992), CR (Gauthier et al., 1999a; Marotta et al., 2001), and in some patients intensively studied by Barton et al. (2001, 2002) and Barton and Cherkasova (2003), whereas it was only partial in patient FB (Riddoch et al., 2008) and was absent in patient PC (Sergent and Signoret, 1992). It should be noted that PC is the only patient reported in Table 3 who had been considered as having a type of "associative prosopagnosia," in contrast with the very high frequency of patients affected by left PCA (and reported in Tables 1 and 2), whose visual recognition defect had been attributed to an associative rather than an apperceptive mechanism. The third observation is that visual object agnosia, which was very often observed in patients with left TO lesions with or without face identification disorders, was rarely observed in right prosopagnosic patients; and in some of these patients, it seemed to specifically affect the categories of animals and other living beings [e.g., patients LH (Etcoff et al., 1991) and CR (Gauthier et al., 1999a)].

Some authors (e.g., Sergent and Signoret, 1992; Wada and Yamamoto, 2001; Uttner et al., 2002) also noticed that objects were usually well recognized from a canonical but not from a non-canonical perspective; but this result is not specific to prosopagnosia. Indeed, since the publication of Warrington and Taylor's (1973, 1978) papers, it is known that difficulty in identifying an object from an unusual perspective is generically linked to damage in the posterior parts of the right hemisphere and is not specific to prosopagnosia.

\section{DISRUPTION OF ANALYTICAL FEATURE-BASED AND HOLISTIC- CONFIGURATIONAL PROCESSES IN PROSOPAGNOSIA}

One of the most striking differences that emerged from this review (and from many previous studies) between the face identification disorders of patients with left TO lesions and of right prosopagnosic patients was the disruption of face processing based on a local, feature-by-feature analysis in patients with left TO lesions and of global, configurational encoding in those with right-sided lesions. This is consistent with the documented importance (e.g., Bradshaw and Nettleton, 1981; Grill-Spector et al., 1998) of the left occipital 
Table 3 | Patients we found in the neuropsychological literature with face recognition disorders resulting from right temporo-occipital lesions.

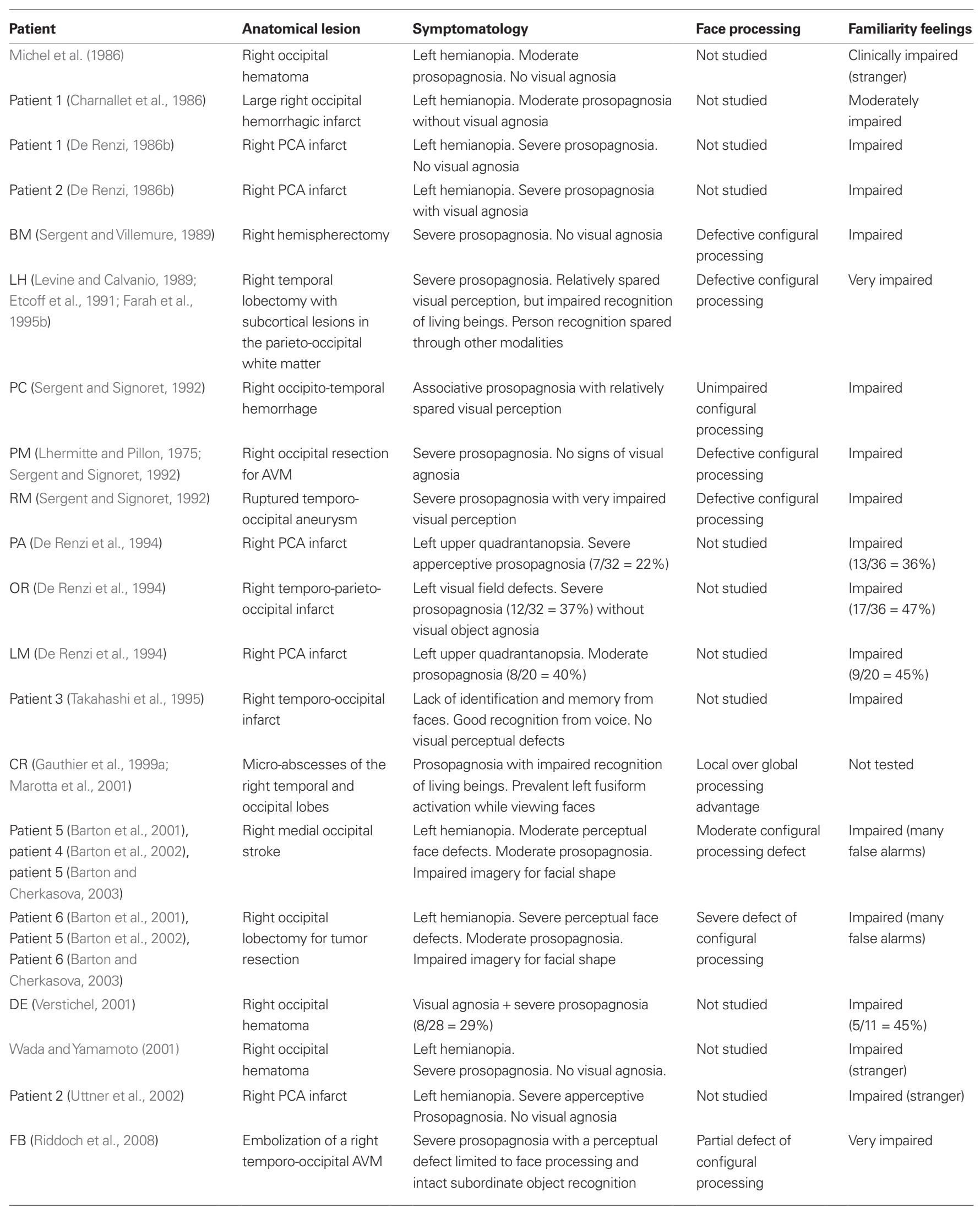


areas for local analysis and of right TO structures for configurational processing. It should be noted, however, that in the right prosopagnosic patients included in our review the severity of this defective configurational process varied from patient to patient and this variability was only in part due to the intrahemispheric locus of lesion. The three patients reported by Sergent and Signoret (1992), for instance, showed different levels of configurational impairment, although the distribution of their lesions was very similar, that is, in all cases encroaching on the right inferior TO cortices and involving the fusiform gyrus. One of the reasons for this reported variability probably stems from the fact that the term "configurational processing" does not denote a unitary mechanism, but refers to a family of more or less related models of normal face recognition. These models agree that perceiving a whole face is more than perceiving its parts and that face inversion disrupts the coding of relational features more than isolated features; however, they disagree as to what is exactly meant by "whole face" and how face inversion disrupts this configurational processing. In fact, Rhodes (1988) and Rhodes et al. (1993) assumed that recognizing a face initially consists of perceiving separate parts or primary features, which are then integrated and give rise to second order features. By contrast, Farah and colleagues (Farah, 1990; Tanaka and Farah, 1993) maintained that face recognition does not start from the encoding of separate parts, but that the face is represented holistically from the onset of visual processing and its parts are only represented in the whole context. Other sources of variability can be found in task-related attentional and temporal factors (Barton et al., 2002) and in the level of expertise attained by the patient (Diamond and Carey, 1986; Gauthier and Tarr, 1997). The influence of attentional and temporal factors is due to the fact that distributed spatial attention and a short response time favor holistic treatment, whereas the instruction to focus on a specific spatial relationship, allowing more time, permits perceiving faces in a more serial manner. On the other hand, the influence of expertise could derive from the fact that the mechanism suggested to mediate the acquisition of expertise is configurational processing. All of the above help clarify why it is equally difficult to find universally accepted criteria to distinguish the "apperceptive" from the "associative" forms of prosopagnosia and a general agreement about the severity of the configurational impairment in prosopagnosia.

\section{LOSS OF FAMILIARITY FEELINGS IN PATIENTS WITH FACE IDENTIFICATION DISORDERS RESULTING FROM UNILATERAL RIGHT AND LEFT TO LESIONS}

One of the most striking results of our comparison between the characteristics of patients with face recognition or identification disorders resulting from right and left TO lesions concerns the study of face familiarity feelings. In fact, these feelings were relatively or completely spared in patients with left TO lesions and systematically impaired in right prosopagnosic patients. It is interesting that the loss of face familiarity feelings is not only considered a hallmark of prosopagnosia by authorities such as Ellis and Young (1988) or Gross and Sergent (1992), but was shown to be the main marker of prosopagnosia in a well designed study by Carlesimo and Caltagirone (1995). In that study, groups of patients with right and left, anterior and posterior brain lesions, with and without prosopagnosia were given tests that required age attribution, unfamiliar faces matching, pointing to familiar faces, and retrieving person-specific semantic information about people whose faces had been judged as familiar. Loss of familiarity feelings was found to be a much more specific marker of right posterior lesions (and of prosopagnosia) than the other tests of apperceptive prosopagnosia or of retrieval of person-specific semantic information. Furthermore, it must be stressed that, just as the expression "configurational processing," also the expression "face familiarity feelings" denotes a family of related phenomena rather than a unitary mechanism. This claim is based on the tendency shown by some patients reviewed in Table 3 (e.g., Barton et al., 2001, 2002) to feel that well known and unknown faces are equally familiar and is confirmed by results obtained in a group study by Rapcsak et al. (1996). These authors showed: (a) that in patients with focal right hemisphere damage, false recognitions, and prosopagnosia can be associated in some patients and dissociated in others; and (b) that the frequency of false recognition errors increases when the lesion extends toward the right frontal areas.

\section{THE DISTINCTION BETWEEN “PROSOPAGNOSIA" AND "MULTIMODAL PEOPLE RECOGNITION DISORDERS"}

In the last part of the Section "Introduction," we stated that even though some patients, in particular those affected by (right) anterior temporal lesions, are unable to recognize familiar people by their faces, they cannot be considered as having "prosopagnosia" because their inability to recognize familiar people is not restricted to faces, but also extends to voices and, to a lesser extent, to names. In order to document this claim, in Table 4 we included all patients found in the literature with face recognition disorders labeled as "prosopagnosia" in the title of their case report and affected by anterior temporal lesions. Our aim was to see whether analogous recognition disorders had been investigated in other modalities and what the outcomes were.

Before discussing the appropriateness of the term "prosopagnosia" to classify the patients reported in Table 4, we will analyze their main characteristics, considering separately: (1) etiology and side of lesion; (2) status of perceptual processes; (3) frequency with which people recognition had been studied through voice and name; (4) outcomes of these investigations; and (5) status of familiarity feelings.

(1) Regarding etiology of the lesion, almost all patients reported in Table 4 suffered from diseases [herpes simple encephalitis (HSE), closed head injury (CHI), or the temporal variant of fronto-temporal degeneration] that preferentially damage the anterior parts of a temporal lobe and almost always involve the "unimpaired" contralateral one. Therefore, from the etiological point of view these patients differed from typical cases of prosopagnosia due to unilateral (right) or bilateral infarcts in the territory of the PCAs. On the other hand, side of lesion was similar in patients with prosopagnosia due to unilateral vascular lesions and in patients with multimodal people recognition disorders, because the lesion affected the right temporal lobe in 8 of the 10 patients reported in Table 4, was bilateral in one (patient 8 of Barton et al., 2001) and left-sided in patient LP (De Renzi, 1986a; De Renzi et al., 1991). Note that in the latter patient prosopagnosia was 
Table 4 | Patients we found in the literature with face recognition disorders labeled as "prosopagnosia" and associated with anterior temporal lesions.

\begin{tabular}{|c|c|c|c|c|c|}
\hline \multirow[t]{2}{*}{ Patient } & \multirow[t]{2}{*}{ Anatomical lesion } & \multirow[t]{2}{*}{ Symptomatology } & \multicolumn{2}{|c|}{ Person recognition through } & \multirow{2}{*}{$\begin{array}{l}\text { Familiarity } \\
\text { feelings }\end{array}$} \\
\hline & & & voice & name & \\
\hline $\begin{array}{l}\text { M.me V. (Boudouresques } \\
\text { et al., 1979), PV (Sergent } \\
\text { and Poncet, 1988, 1990) }\end{array}$ & $\begin{array}{l}\text { HSE with massive damage of } \\
\text { the anterior parts of the right } \\
\text { temporal lobe }\end{array}$ & $\begin{array}{l}\text { Selective defect of familiar } \\
\text { people recognition. Unaware or } \\
\text { poor voice recognition }\end{array}$ & Impaired & Not tested & Not tested \\
\hline $\begin{array}{l}\text { LP: Patient } 5 \text { (De Renzi, } \\
\text { 1986a; De Renzi et al., } \\
\text { 1987a) }\end{array}$ & $\begin{array}{l}\text { HSE with lesion of the } \\
\text { anterior and inferior parts of } \\
\text { the left temporal lobe }\end{array}$ & $\begin{array}{l}\text { Severe defect of familiar people } \\
\text { recognition and semantic } \\
\text { memory disorders (mainly for } \\
\text { vegetables) }\end{array}$ & Impaired & Impaired & $\begin{array}{l}\text { More impaired } \\
\text { for faces than } \\
\text { for names }\end{array}$ \\
\hline $\begin{array}{l}\text { VA: Case } 3 \text { (De Renzi } \\
\text { et al., 1991) }\end{array}$ & $\begin{array}{l}\text { HSE with lesion confined to } \\
\text { the right temporal lobe }\end{array}$ & $\begin{array}{l}\text { Moderate defect of familiar } \\
\text { people recognition when seen } \\
\text { out of context }\end{array}$ & Not tested & Not tested & $\begin{array}{l}\text { Very impaired } \\
\text { for faces }\end{array}$ \\
\hline $\begin{array}{l}\text { MT (Schweinberger et al., } \\
\text { 1995; Henke et al., 1998) }\end{array}$ & Right temporo-parietal infarct & $\begin{array}{l}\text { Severe defect of familiar people } \\
\text { recognition from faces (1/18), } \\
\text { without signs of visual agnosia. } \\
\text { Poor memory for faces, but not } \\
\text { for words }\end{array}$ & Not tested & Impaired (13/18) & Impaired \\
\hline VH (Evans et al., 1995) & $\begin{array}{l}\text { Diffuse atrophy of the right } \\
\text { antero-inferior temporal lobe }\end{array}$ & $\begin{array}{l}\text { Progressive defect recognizing } \\
\text { familiar people with mild } \\
\text { memory disorders }\end{array}$ & $\begin{array}{l}\text { Initially clinically } \\
\text { unimpaired }\end{array}$ & $\begin{array}{l}\text { Normal retrieval of } \\
\text { semantic } \\
\text { information }\end{array}$ & $\begin{array}{l}\text { Moderate } \\
\text { impairment } \\
\text { for faces }\end{array}$ \\
\hline $\begin{array}{l}\text { Patient } 8 \text { (Barton et al., 2001), } \\
\text { patient } 1 \text { (Barton et al., 2002), } \\
\text { patient } 8 \text { (Barton and } \\
\text { Cherkasova, 2003) }\end{array}$ & $\begin{array}{l}\text { Bilateral anterior temporal } \\
\text { lobe damage from } \mathrm{CHI} \text { and } \\
\text { right temporal lobe resection }\end{array}$ & $\begin{array}{l}\text { Severe defect of familiar people } \\
\text { recognition with impairment on } \\
\text { the Benton FRT }\end{array}$ & Not tested & Not tested & $\begin{array}{l}\text { Very impaired } \\
\text { for faces }\end{array}$ \\
\hline FG (Joubert et al., 2003) & $\begin{array}{l}\text { Prevalent atrophy of the right } \\
\text { fusiform gyrus; relative } \\
\text { sparing of the anterior } \\
\text { temporal cortex }\end{array}$ & $\begin{array}{l}\text { Progressive defect recognizing } \\
\text { familiar people with impaired } \\
\text { configurational processing }\end{array}$ & $\begin{array}{l}\text { Initially the } \\
\text { voice of the } \\
\text { person helped } \\
\text { recognition }\end{array}$ & $\begin{array}{l}\text { Normal retrieval of } \\
\text { semantic } \\
\text { information from } \\
\text { name }\end{array}$ & $\begin{array}{l}\text { Mildly } \\
\text { impaired for } \\
\text { faces }\end{array}$ \\
\hline BD (Williams et al., 2006) & $\begin{array}{l}\text { Right anterior temporal lobe } \\
\text { atrophy }\end{array}$ & $\begin{array}{l}\text { Progressive defect recognizing } \\
\text { familiar people, with impaired } \\
\text { configurational processing but } \\
\text { spared semantic information }\end{array}$ & Not tested & $\begin{array}{l}\text { Normal retrieval of } \\
\text { semantic } \\
\text { information from } \\
\text { name }\end{array}$ & $\begin{array}{l}\text { Moderately } \\
\text { impaired for } \\
\text { faces }\end{array}$ \\
\hline LR (Bukach et al., 2006) & $\begin{array}{l}\text { Traumatic lesion of the right } \\
\text { antero-inferior temporal lobe; } \\
\text { sparing the fusiform gyrus }\end{array}$ & $\begin{array}{l}\text { Moderate defect of familiar } \\
\text { people recognition when seen } \\
\text { out of context }\end{array}$ & Not tested & Not tested & $\begin{array}{l}\text { Impaired } \\
\text { (many false } \\
\text { alarms) }\end{array}$ \\
\hline $\begin{array}{l}\text { MT (Nakachi and } \\
\text { Muramatsu, 2007) }\end{array}$ & $\begin{array}{l}\text { Atrophy of the right anterior } \\
\text { temporal lobe }\end{array}$ & $\begin{array}{l}\text { Selective form of associative } \\
\text { prosopagnosia }\end{array}$ & Spared & Spared & $\begin{array}{l}\text { Impaired for } \\
\text { faces }\end{array}$ \\
\hline
\end{tabular}

associated with severe semantic disorders, like the patients with face recognition disorders resulting from left TO lesions we reported in Table 2 .

(2) Perceptual processes were intact in most patients reported in Table 4, but an impairment of configurational processing was described in patients FG (Joubert et al., 2003) and BD (Williams et al., 2006). In patient FG, this unexpected finding was probably due to atypical distribution of the temporal lobe atrophy, which involved the right fusiform gyrus and the parahippocampal cortex, and relatively spared the temporo-polar cortex; however, patient BD's impaired configurational processes could not be explained, because of the atypical method used to assess them and the poor description of atrophy.
(3) Regarding the frequency with which voice recognition and retrieval of person-specific semantic information from names had been studied, they had not been systematically investigated (or in any case had not been reported) in about half of these patients (it must be acknowledged, however, that usually this information was also lacking for the patients reported in Tables 2 and 3 ).

(4) With respect to outcomes of the investigations concerning voice and name recognition, voice recognition was impaired in two (M.me V and LP) and spared in three (VH, FG, and MT) of the five patients in whom it had been studied. This last result must, however, be evaluated with caution because voice recognition had been considered as intact on the basis 
of a purely clinical judgment in patients VH (Evans et al., 1995) and FG (Joubert et al., 2003) and of a short clinical task in patient MT (Nakachi and Muramatsu, 2007).

Results obtained by analyzing the retrieval of person-specific semantic information from names are rather different, because this ability was severely impaired only in patient LP (De Renzi, 1986; De Renzi et al., 1991), who was affected by a left temporal lesion and showed severe semantic disorders, and mildly impaired in patient MT (Schweinberger et al., 1995). Retrieval of person-specific semantic information from names was, on the contrary, unimpaired in most right anterior temporal patients in whom it had been studied, namely in patients VA (Evans et al., 1995), FG (Joubert et al., 2003), BD (Williams et al., 2006), and MT (Nakachi and Muramatsu, 2007). These findings are consistent with results of a recent review (Gainotti, 2007a) of the patterns of famous people recognition in patients with right and left anterior temporal lesions.

(5) Regarding face familiarity feelings, they were more or less severely impaired in all patients (9 out of 10) in whom they had been investigated. This result is quite similar to that obtained in the prosopagnosic patients with right TO lesions reported in Table 3 and confirms the importance of the loss of familiarity feelings in defects of known faces recognition disorders resulting from right hemisphere lesions.

Taken together, the data reported in Table 4 suggest the need for caution in using the term "prosopagnosia" to denote the face recognition disorders of patients with right anterior temporal lesions. In fact, in a few patients (e.g., VH, FG, and MT) this term seems appropriate, whereas in other patients (e.g., M.me V, LP, and MT) the term "multimodal people recognition disorders" is more appropriate, and in others we lack data about voice and name recognition that would allow distinguishing a form of "prosopagnosia" from a form of "multimodal people recognition disorders."

\section{GENERAL DISCUSSION}

The main results of this review concern, on one hand, the qualitative differences between defects of visual recognition observed in patients with lesions involving the ventral TO structures of the right and left hemisphere and, on the other hand, the distinction between "prosopagnosia" and "multimodal people recognition disorders." This second point of our review has led us to take into account aspects of familiar people recognition (such as the voice or the name) that clearly exceed the specific issue of prosopagnosia. This was made with two aims in mind: (a) to place the discussion of prosopagnosia in the more general context of familiar people recognition disorders; (b) to stress the need of investigating the other modalities of people recognition before considering a patients with face recognition disorders as an instance of prosopagnosia. In order to clarify the various parts of this discussion, we have reported in Figure 1 the critical areas of the right and left temporal and occipital lobes that could play a critical role in different varieties of prosopagnosia and of multimodal familiar people recognition disorders:

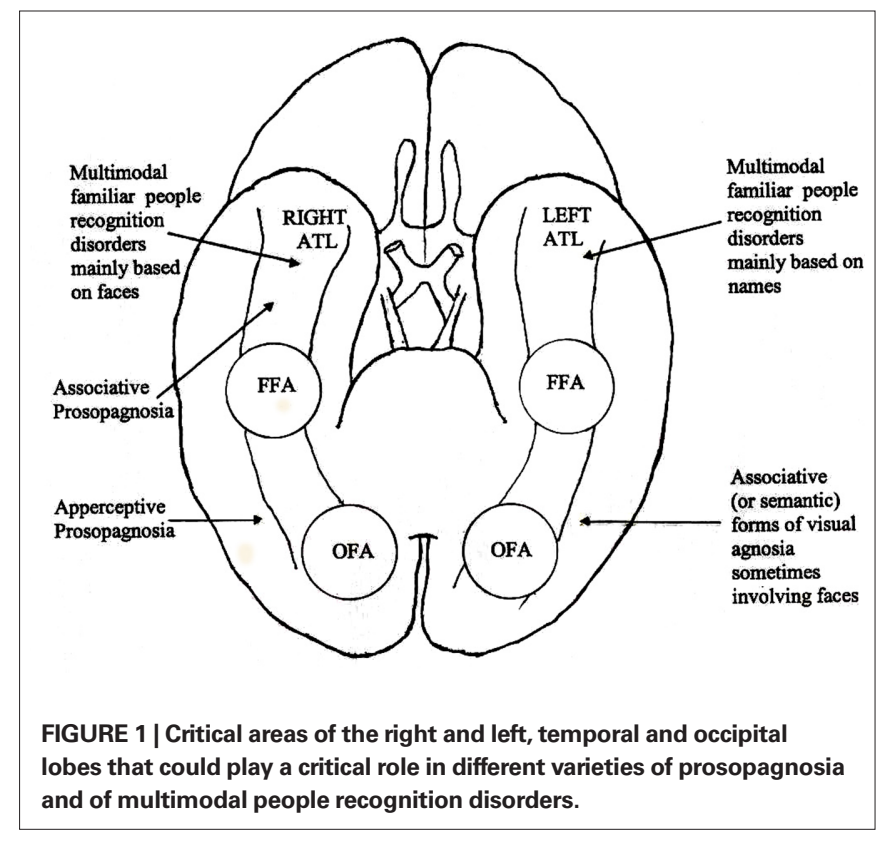

\section{QUALITATIVE DIFFERENCES BETWEEN THE VISUAL RECOGNITION DISORDERS OF PATIENTS WITH LESIONS INVOLVING THE VENTRAL TO STRUCTURES OF THE RIGHT AND LEFT HEMISPHERE}

Although important qualitative differences and a different clinical context were observed in face recognition and identification disorders associated with right and left TO lesions, only those resulting from right-sided lesions fully satisfied the criteria of a modalityspecific recognition disorder selectively affecting familiar faces (prosopagnosia). This claim is based on the following: (a) the type of perceptual processing disrupted in these patients is the holisticconfigurational one, which is considered most appropriate for the perceptual treatment of faces (Bradshaw and Nettleton, 1981; Rhodes, 1988; Grill-Spector et al., 1998); (b) right brain-damaged patients show a systematic loss of face familiarity feelings, which can be considered the main mechanism through which we automatically orient attention toward socially relevant known people and disregard unknown ones.

Patients with left TO lesions can also rarely show defects of familiar people identification, but these defects are usually included in a context of associative visual object agnosia or of more general semantic disorders, as shown by data reported in Tables $\mathbf{1}$ and 2 .

This interpretation might also explain why these patients, in whom faces are processed normally in a configurational manner by the right hemisphere, do not show the loss of face familiarity feelings, which is a hallmark of true prosopagnosia.

More generally, the fact that the two markers of prosopagnosia resulting from disruption of the TO structures of the right hemisphere consist of (a) a defect in face configurational processing and (b) a loss of face familiarity feelings, raises the issue about the relationships that might exist between these two right hemisphere processing mechanisms. One hypothesis that might be advanced on this subject could consist in assuming that a sort of functional integration may exist between the coarse holistic treatment of faces 
performed by the right hemisphere and the emergence of familiarity feelings, aiming to check that the person who has raised these feelings really corresponds to the tentatively identified people. The hypothesis of a link between defective face configurational processing and impaired face familiarity feelings could explain the strong correlation observed in patients with a lesion involving the ventral TO areas of the right hemisphere (reported in Table 3 ), between defective configurational processing and lack of familiarity feelings.

This hypothesis could also explain why in patients with a lesion involving the territory of the left PCA (Table 2) face recognition disorders often satisfied the criteria of associative prosopagnosia, whereas in those with a lesion involving the ventral TO areas of the right hemisphere (Table 3 ) the defect was not limited to the recognition of familiar faces but also extended to the discrimination of unfamiliar faces. This was probably because in patients with right hemisphere lesions the defect of configurational processing, typical of the right ventral TO areas, concerned both familiar and unfamiliar faces and therefore made the generation of the associative form of prosopagnosia (Table 3) very difficult, whereas in patients with homologous lesions of the left hemisphere the associative nature of visual agnosias concerning objects and faces (Tables 1 and 2) could have been due to the mnesic/semantic nature of their recognition disorders.

\section{DISTINCTION BETWEEN “PROSOPAGNOSIA" AND “MULTIMODAL PEOPLE RECOGNITION DISORDERS"}

The distinction between "prosopagnosia" and "multimodal people recognition disorders" is probably based on the different functions accomplished in the earliest and in the last stages of face processing by the posterior (TO) and the anterior parts of the right temporal lobe.

According to a classical feed-forward model (Haxby et al., 2000), the more posterior face-sensitive regions of the visual cortex (OFA) could be involved in basic analysis of facial features and could project to more anterior regions (FFA), which could encode the structural face properties related to identity processing (Fox et al., 2008). Other more dynamic models (e.g., Rossion et al., 2003; Sorger et al., 2007) suggest that not only feed-forward, but also re-entrant interactions between right and left OFA and FFA could play a role in normal face perception; in any case, disruption of these TO structures selectively impairs visual perception, leading to an apperceptive form of prosopagnosia.

In the anterior temporal structures, on the contrary, visual processing output is associated with the output of other sensory modalities and with the mechanisms of episodic and semantic memory.

Impairment of these structures should, therefore, rarely provoke a modality-specific face recognition defect, but rather a multimodal person recognition disorder in which defects of face recognition are sometimes prominent. According to some authors (e.g., Mohedano-Moriano et al., 2008; Joassin et al., 2011) the right hippocampus could play a particular role in the integration of face and voice information, because this structure has an enhanced connectivity with both visual (the FFA) and auditory (the superior temporal gyrus) unimodal cortical areas. Anyway, irrespectively of the role that hippocampus and peri-rhinal cortex could play in the multimodal integration of face and voice information and in the generation of face familiarity feelings (see Yonelinas, 2002;
Gainotti, 2007b for reviews), it remains possible that some patients with right anterior temporal lesions may show a form of associative prosopagnosia. This variety of prosopagnosia could result from a disconnection (Fox et al., 2008) between anterior temporal structures and the FFA, or from the earliest cortical lesions, marking the onset of a right temporal variant of fronto-temporal degeneration. The hypothesis that "associative prosopagnosia" may be the first manifestation of a right temporal variant of fronto-temporal degeneration is, at first glance, supported by the data reported in Table 4. If we look at these data, we see that two patients (VA and MT) could satisfy the criteria for associative prosopagnosia, because they have a famous face recognition defect, but no visual perceptual defects, voice recognition disorders or defects in the retrieval of person-specific semantic information from names. Nevertheless, caution is required in concluding that these are true cases of associative prosopagnosia, because in patient MT voice recognition was considered unimpaired on the basis of a very short clinical task, and in patient VA the integrity of voice recognition was based on her statement that difficulty in recognizing familiar people lessened when she heard their voices. However, both M.me V of Boudouresques et al. (1979) and our patient CO (Gainotti et al., 2003) repeatedly claimed they were able to identify familiar people by hearing their voices but performed very poorly when voice identification was systematically investigated. And voice recognition was as impaired as face recognition in other patients with face recognition disorders associated with right anterior temporal lesions (e.g., BD, Hanley et al., 1989; KS, Ellis et al., 1989; Maria, Gentileschi et al., 1999; Emma, Gentileschi et al., 2001; CD, Gainotti et al., 2008; MD, Busigny et al., 2009; KL, Hailstone et al., 2010) who were not reported in Table 4 because they had not been labeled as prosopagnosia in the title of their case report. Taken together, these data indicate that in patients with anterior temporal lesions and familiar face recognition disorders a systematic investigation of voice recognition and retrieval of person-specific semantic information from names is necessary to decide whether the patient should be considered as having a form of "associative prosopagnosia" or a form of "multimodal people recognition disorder."

\section{CONCLUDING REMARKS}

In the introductory part of this review, we listed some issues (such as the specific or non-specific manifestations of prosopagnosia, the unitary or non-unitary nature of this syndrome and the mechanisms underlying face recognition disorders) that are still controversial in the study of prosopagnosia. We also suggested that two main sources of variance might be the qualitative differences between the face recognition disorders observed in patients with a prevalent lesion of the right or left hemisphere and in those with a lesion encroaching upon the TO or the (right) anterior temporal cortical areas.

Results of our review confirm that different kinds of face recognition disorders can be observed as a function of the right vs left and of the TO vs (right) anterior temporal lesion location. In fact, they show that the most specific forms of prosopagnosia are due to lesions of a right posterior network, including the OFA and the FFA, whereas (a) the face identification defects observed in patients with left TO lesions seem due to a semantic defect impeding access to the person-specific semantic information from the visual modality 
and (b) the face recognition defects resulting from right anterior temporal lesions can usually be considered as part of a multimodal people recognition disorder.

From the operational point of view, our results suggest: (a) considering the components of visual agnosia often observed in prosopagnosic patients with bilateral TO lesions as part of a semantic

\section{REFERENCES}

Albert, M. L, Reches, A., and Silverberg, R. (1975). Associative visual agnosia without alexia. Neurology 25, 322-326.

Anaki, D., Kaufman, Y., Freedman, M., and Moscovitch, M. (2007). Associative (prosop)agnosia without (apparent) perceptual deficits: a case-study. Neuropsychologia 45, 1658-1671.

Atkinson, R. C., and Juola, J. F. (1974). "Search and decision processes in recognition memory," in Contemporary Developments in Mathematical Psychology, Vol. 1, Learning, Memory and Thinking, eds D. H. Krantz, R. C. Atkinson, R. D. Luce, and P. Suppes (San Francisco: Freeman), 243-293.

Barton, J. J. (2008). Prosopagnosia associated with a left occipitotemporal lesion. Neuropsychologia 46, 2214-2224.

Barton, J. J., and Cherkasova, M. (2003). Face imagery and its relation to perception and covert recognition in prosopagnosia. Neurology61, 220-225.

Barton, J. J., and Cherkasova, M, O'Connor M. (2001). Covert recognition in acquired and developmental prosopagnosia. Neurology 57 , 1161-1168.

Barton, J. J., Press, D. Z., Keenan, J. P., and O'Connor, M. (2002). Lesions of the fusiform face area impair perception of facial configuration in prosopagnosia. Neurology 58, 71-78.

Benton, A. (1990). Facial recognition (1990). Cortex 26, 491-499.

Benton, A. L., and Van Allen, M.W. (1968). Impairment of facial recognition in patients with cerebral disease. Cortex 4, 344-358.

Bever, T. G., and Chiarello R. J. (2009). Cerebral dominance in musicians and nonmusicians. J. Neuropsychiatry Clin. Neurosci. 21, 94-97.

Bodamer, J. (1947). Die prosopagnosie. Arch. Psychiatr. Nervenkr. 179, 6-53.

Boudouresques, J., Poncet, M, Cherif, A. A., and Balzamo, M. (1979). Agnosia for faces: evidence of functional disorganization of a certain type of recognition of objects in the physical world. Bull. Acad. Natl. Med. 163, 695-702.

Bradshaw, J. L., and Nettleton, N. C. (1981). The nature of hemispheric specialization in man. Behav. Brain Sci. 4, 51-91.

Bukach, C. M., Bub, D. N., Gauthier, I., and Tarr, M. J. (2006). Perceptual expertise effects are not all or none: spatially limited perceptual expertise for faces in a case of prosopagnosia. $J$. Cogn. Neurosci. 18, 48-63.

Busigny, T., Graf,M., Mayer,E., and Rossion, B. (2010a). Acquired prosopagnosia as a face-specific disorder: ruling out the general visual similarity account. Neuropsychologia 48, 2051-2067.

Busigny, T., Joubert, S., Felician, O., Ceccaldi, M., and Rossion, B. (2010b). Holistic perception of the individual face is specific and necessary: evidence from an extensive case study of acquired prosopagnosia. Neuropsychologia 48, 4057-4092.

Busigny, T, Robaye, L., Dricot, L., and Rossion, B. (2009). Right anterior temporal lobe atrophy and person-based semantic defect: a detailed case study. Neurocase 15, 485-508.

Carlesimo, G. A., and Caltagirone, C. (1995). Components in the visual processing of known and unknown faces. J. Clin. Exp. Neuropsychol. 17, 691-705.

Carlesimo, G. A., Casadio, P., Sabbadini, M., and Caltagirone, C. (1998). Associative visual agnosia resulting from a disconnection between intact visual memory and semantic systems. Cortex 34, 563-576.

Charnallet, A., Carbonnel, S., et al. (1986). Prosopagnosia: a comparative study of two cases. Paper Presented at the 4th Bressanone Meeting of Cognitive Neuropsychology.

Damasio, A. R., Damasio, H., and Van Hoesen, G. W. (1982). Prosopagnosia: anatomic basis and behavioural mechanisms. Neurology 32, 331-341.

Damasio, A., Tranel, D., and Damasio, H. (1988). "Deep prosopagnosia": A new form of acquired face recognition defect caused by left hemisphere damage. Neurology 38 (Suppl.1), 72.

Damasio, A. R., Tranel, D., and Damasio, H. (1990). Face agnosia and the neural substrates of memory. Annu. Rev. Neurosci. 13, 89-109.

Davidoff, J., and Landis, T. (1990). Recognition of unfamiliar faces in prosopagnosia. Neuropsychologia 28, 1143-1161.

Delvenne, J. F., Seron, X., Coyette, F., and Rossion, B. (2004). Evidence for perceptual deficits in associative visual (prosop)agnosia: a single-case study. Neuropsychologia 42, 597-612.

De Renzi, E. (1986a). "Current issues in prosopagnosia," in Aspects of Face

defect resulting from the left-sided lesion (and not of prosopagnosia proper); (b) systematically investigating voice recognition disorders in patients with right anterior temporal lesions to determine whether the patient's face recognition defect should be considered a form of "associative prosopagnosia" or a form of "multimodal people recognition disorder."

Processing, eds H. D. Ellis, M. A. Jeeves, F. Newcombe, and A. Young (Dordrecht: Martinus Nisoff), 243-252.

De Renzi, E. (1986b). Slowly progressive visual agnosia or apraxia without dementia. Cortex 22, 171-180.

De Renzi, E. (2000). Disorders of visual recognition. Semin. Neurol. 20, 479-485.

De Renzi, E., and di Pellegrino, G. (1998). Prosopagnosia and alexia without object agnosia. Cortex 34, 403-415.

De Renzi, E., Faglioni, P., Grossi, D., and Nichelli, P. (1991). Apperceptive and associative forms of prosopagnosia. Cortex 27, 213-221.

De Renzi, E., Liotti, M., and Nichelli, P. (1987a). Semantic amnesia with preservation of autobiographic memory: a case report. Cortex 23, 575-597.

De Renzi, E., Zambolin, A., and Crisi, G. (1987b). The pattern of neuropsychological impairment associated with left posterior cerebral artery infarcts. Brain 110, 1099-1116.

De Renzi, E., Perani, D., Carlesimo, G. A., Silveri, M. C., and Fazio, F. (1994). Prosopagnosia can be associated with damage confined to the right hemisphere. An MRI and PET study and a review of the literature. Neuropsychologia 32, 893-902.

Diamond,R.,and Carey,S. (1986). Why faces are and are not special: an effect of expertise. J. Exp. Psychol. Gen. 115, 107-117.

Dixon, M. J., Bub, D. N., and Arguin, M. (1998).Semantic and visual determinants of face recognition in a prosopagnosic patient. J. Cogn. Neurosci. 10, 362-376.

Duchaine, B. C., and Nakayama, K. (2006). The Cambridge Face Memory Test: results for neurologically intact individuals and an investigation of its validity using inverted face stimuli and prosopagnosic participants. Neuropsychologia 44, 576-585.

Duchaine, B. C., and Weidenfeld, A. (2003). An evaluation of two commonly used tests of unfamiliar face recognition. Neuropsychologia 41, 713-720.

Ellis, A. W., and Young, A. W. (1988). Human Cognitive Neuropsychology. Hove: Lawrence Erlbaum.

Ellis, A. W., Young, A. W., and Critchley, E. M. R. (1989). Loss of memory for people following temporal lobe damage. Brain 112, 1469-1483.
Etcoff, N., Freeman R, and Cave KR. (1991).Can we lose memories of faces? Content specificity and awareness in a prosopagnosic. J. Cogn. Neurosci. 3 , 25-41.

Evans, J. J., Heggs, A. J., Antoun, N., and Hodges, J. R. (1995). Progressive prosopagnosia associated with selective right temporal lobe atrophy. Brain $118,1-13$.

Farah, M. (1990). Visual Agnosia: Disorders of Visual Recognition and What They Tell Us About Normal Vision. Cambridge: MIT Press.

Farah, M. J., Levinson, K. L., and Klein, K. L. (1995a). Face perception and withincategory discrimination in prosopagnosia. Neuropsychologia 33, 661-674.

Farah, M. J., Tanaka, J. W., and Drain, H. M. (1995b). What causes the face inversion effect? J. Exp. Psychol. Hum. Percept. Perform. 21, 628-634.

Feinberg, T. E., Rothi, L. J., and Heilman, K. M. (1986). Multimodal agnosia after unilateral left hemisphere lesion. Neurology 36, 864-867.

Feinberg, T. E., Schindler, R. J., Ochoa, E., Kwan, P. C., and Farah, M. J. (1994). Associative visual agnosia and alexia without prosopagnosia. Cortex 30 , 395-411.

Ferro, J. M., and Santos, M. E. (1984). Associative visual agnosia: a case study. Cortex 20, 121-134.

Fox, C. J., Iaria, G., and Barton, J. J. (2008). Disconnection in prosopagnosia and face processing. Cortex 44, 996-1009.

Gainotti, G. (2007a). Different patterns of famous people recognition disorders in patients with right and left anterior temporal lesions: a systematic review. Neuropsychologia 45, 1591-1607.

Gainotti, G. (2007b). Face familiarity feelings, the right temporal lobe and the possible underlying neural mechanisms. Brain Res. Rev. 56, 214-235.

Gainotti, G. (2010). Not all patients labeled as "prosopagnosia" have a real prosopagnosia. J. Clin. Exp. Neuropsychol. 32, 763-766.

Gainotti, G., Barbier, A., and Marra, C. (2003). Slowly progressive defect in recognition of familiar people in a patient with right anterior temporal atrophy. Brain 126, 792-803.

Gainotti, G., Ferraccioli M., Quaranta D., and Marra C. (2008). Cross-modal recognition disorders for persons and other unique entities in a patient with 
right fronto-temporal degeneration. Cortex 44, 238-248.

Gallois, P., Ovelacq, E., Hautecoeur, P., and Dereux, J.F. (1988). Disconnection and recognition of faces. A case with lesions of the left visual cortex and the splenium. Rev. Neurol. (Paris) 144, 113-119.

Gauthier, I., Behrmann M., and Tarr, M. J. (1999a). Can face recognition really be dissociated from object recognition? J. Cogn. Neurosci. 11, 349-370.

Gauthier, I., Tarr, M. J., Anderson, A. W., Skudlarski, P., and Gore, J. C. (1999b). Activation of the middle fusiform 'face area' increases with expertise in recognizing novel objects. Nat. Neurosci. 2, 568-573.

Gauthier, I., and Nelson, C. A. (2001). The development of face expertise. Curr. Opin. Neurobiol. 11, 219-224.

Gauthier, I., and Tarr, M. J. (1997). Becoming a "Greeble" expert: exploring mechanisms for face recognition. Vision Res. 37, 1673-1682.

Gauthier, I., Tarr, M. J., Moylan, J., Skudlarski, P., Gore, J. C., and Anderson, A.W. (2000). The fusiform "face area" is part of a network that processes faces at the individual level. J. Cogn. Neurosci. 12, 495-504.

Gentileschi, V., Sperber, S., and Spinnler, H. (1999). Progressive defective recognition of familiar people. Neurocase 5, 407-424.

Gentileschi, V., Sperber, S., and Spinnler, H. (2001). Crossmodal agnosia for familiar people as a consequence of right infero-polar temporal atrophy. Cogn. Neuropsychol. 18, 439-463.

Grill-Spector, K., Kushnir, T., Hendler T., Edelman, S., Itzchak, Y., and Malach, R. (1998). A sequence of object-processing stages revealed by fMRI in the human occipital lobe. Hum. Brain Mapp. 6, 316-328.

Gross, C. G., and Sergent, J. (1992). Face recognition. Curr. Opin. Neurobiol. 2, 156-161.

Hailstone, J. C., Crutch, S. J., Vestergaard, M. D., Patterson, R. D., and Warren, J. D. (2010). Progressive associative phonagnosia: a neuropsychological analysis. Neuropsychologia 48, 1104-1114.

Hanley, J. R., Young, A. W., and Pearson, N. A. (1989). Defective recognition of familiar people. Cogn. Neuropsychol. 6, 179-210.

Haxby, J.V., Hoffman, E. A., and Gobbini, M. I. (2000). The distributed human neural system for face perception. Trends Cogn. Sci. 4, 223-233.

Henke, K., Schweinberger, S. R., Grigo, A., Klos, T., and Sommer, W. (1998). Specificity of face recognition: recognition of exemplars of non-face objects in prosopagnosia. Cortex 34, 289-296.

Joassin, F., Pesenti, M., Maurage, P., Verreckt, E., Bruyer, R., and Campanella, S. (2011). Cross-modal interactions between human faces and voices involved in person recognition. Cortex 47, 367-376.

Joubert, S., Felician, O., Barbeau, E., Sontheimer, A., Barton, J. J., Ceccaldi, M., and Poncet, M. (2003). Impaired configurational processing in a case of progressive prosopagnosia associated with predominant right temporal lobe atrophy. Brain 126, 2357-2350.

Kanwisher, N. (2000). Domain specificity in face perception. Nat. Neurosci. 3, 759-763.

Kanwisher, N., McDermott, J., and Chun, M. M. (1997). The fusiform face area: a module in human extrastriate cortex specialized for face perception. $J$. Neurosci. 17, 4302-4431.

Levine, D. N., and Calvanio, R. (1989). Prosopagnosia: a defect in visual configural processing. Brain Cogn. $10,149-170$.

Lhermitte, F., Chain, F., Escourolle, R., Ducarne, B., and Pillon, B. (1972). Anatomoclinical study of a case of prosopagnosia. Rev. Neurol. (Paris) 126, 329-346.

Lhermitte, F., and Pillon, B. (1975). La prosopagnosie. Role de l'hémisphère droit dans la perception visuelle. Rev. Neurol. (Paris) 131, 791-812.

Lissauer, H. (1890). Ein fall von seelenblindheit nebst einem beitrag zur theorie derselben. Arch. Psychiatr. 21, 222-270.

Marotta, J. J., Genovese, C. R., and Behrmann, M. (2001). A functional MRI study of face recognition in patients with prosopagnosia. Neuroreport 12, 1581-1587.

Mattson, A. J., Levin H. S., and Grafman J. (2000). A case of prosopagnosia following moderate closed head injury with left hemisphere focal lesion. Cortex 36, 125-137.

McCarthy, R. A., and Warrington, E. K. (1986). Visual associative agnosia: a clinico-anatomical study of a single case. J. Neurol. Neurosurg. Psychiatry 49, 1233-1240.

McNeil, J. E., and Warrington, E. K. (1993). Prosopagnosia: a face-specific disorder. Q. J. Exp. Psychol. A. 46, 1-10.

Michel, F., Perenin, M. T., and Sieroff, F. (1986). Prosopagnosie sans hemianopsie après lésion unilatérale occipitotemporale droite. Rev. Neurol. (Paris) $142,545-554$.

Mohedano-Moriano, A., MartinezMarcos, A., Pro-Sistiaga, P., Blaizot, X., Arroyo-Jimenez, M. M., Marcos, P., Artacho-Pérula, E., and Insausti, R. (2008). Convergence of unimodal and polymodal sensory input to the entorhinal cortex in the fascicularis monkey. Neuroscience 151, 55-71.

Nakachi, R., and Muramatsu, T. (2007). Progressive prosopagnosia at the very early stage of frontotemporal lobar degeneration. Psychogeriatrics 7, 155-162.

Peretz, I. (1990). Processing of local and global musical information by unilateral brain-damaged patients. Brain 113, 1185-1205.

Pillon, B., Signoret, J. L., and Lhermitte, F. (1981). Associative visual agnosia: role of the left hemisphere in visual perception. Rev. Neurol. (Paris) 137,831-842.

Rapcsak, S.Z., Polster, M. R., Glisky, M. L., and Comer, J. F. (1996). False recognition of unfamiliar faces following right hemisphere damage: neuropsychological and anatomical observations. Cortex 32, 593-611.

Rhodes, G. (1988). Looking at faces: first-order and second-order features as determinants of facial appearance. Perception 17, 43-63.

Rhodes, G., Brake, S., and Atkinson, A. (1993). What's lost in inverted faces? Cognition 47, 25-57.

Riddoch, M. J., Johnston, R. A., Bracewell, R. M., Boutsen, L., and Humphreys, G. W. (2008). Are faces special? A case of pure prosopagnosia. $\operatorname{Cog} n$. Neuropsychol. 25, 3-26.

Rossion, B., Caldara, R., Seghier, M., Schuller,A.M., Lazeyras. F., and Mayer, E. (2003). A network of occipito-temporal face-sensitive areas besides the right middle fusiform gyrus is necessary for normal face processing. Brain 126, 2381-2395.

Schiltz, C., and Rossion, B. (2006). Faces are represented holistically in the human occipito-temporal cortex. Neuroimage 32, 1385-1394.

Schweinberger, S. R., Klos, T., and Sommer, W. (1995). Covert face recognition in prosopagnosia: a dissociable function? Cortex 31, 517-529.

Sergent, J., and Poncet, M. (1988). Patterns of perceptual deficits in 2 prosopagnosic patients. J. Clin. Exp. Neuropsychol. 10, 50.

Sergent, J., and Poncet, M. (1990). From covert to overt recognition of faces in a prosopagnosic patient. Brain 113, 989-1004.

Sergent, J., and Signoret, J. L. (1992). Varieties of functional deficits in prosopagnosia. Cereb. Cortex 2, 375-388.

Sergent, J., and Villemure, J. G. (1989). Prosopagnosia in a right hemispherectomized patient. Brain 112, 975-995.

Sorger, B., Goebel, R., Schiltz, C., and Rossion, B. (2007). Understanding the functional neuroanatomy of acquired prosopagnosia. Neuroimage $35,836-852$.

Takahashi, N., Kawamura, M., Hirayama, K., Shiota, J., and Isono, O. (1995). Prosopagnosia: a clinical and anatomical study of four patients. Cortex $31,317-329$.
Tanaka, J.W., and Farah, M. J. (1993). Parts and wholes in face recognition. Q. J. Exp. Psychol. 46, 225-245.

Tzavaras, T., Merienne L., and Masure, M. C. (1973). Prosopagnosie, amnésie et troubles du langage par lésion temporale gauche chez un sujet gaucher. Encéphale 62, 382-394.

Uttner, I., Bliem, H., and Danek, A. (2002). Prosopagnosia after unilateral right cerebral infarction. J. Neurol. 249, 933-935.

Verstichel, P. (2001). Troubles de la reconnaissance des visages: reconnaissance implicite, sentiment de familiarité, role de chaque hémisphère. Bull. Acad. Natl. Med. 185, 537-553.

Verstichel, P., and Chia, L. (1999). Troubles de l'identification des visages après lésion hémisphérique gauche. Rev. Neurol. (Paris) 155, 937-943.

Yonelinas, A. P. (2002). The nature of recollection and familiarity: a review of 30 years of research. J. Mem. Lang. 46, 441-517.

Wada, Y., and Yamamoto, T. (2001). Selective impairment of facial recognition due to a haematoma restricted to the right fusiform and lateral occipital region. J. Neurol. Neurosurg. Psychiatry 71, 254-257.

Warrington, E. K., and Taylor, A. M. (1973). The contribution of the right parietal lobe to object recognition. Cortex 9, 152-164.

Warrington, E. K., and Taylor, A. M. (1978). Two categorical stages of object recognition. Perception 7, 695-705.

Williams, M.A., Savage, G., and Halmagyl, M. (2006). Abnormal configural face perception in a patient with right anterior temporal lobe atrophy. Neurocase 12, 286-291.

Yin, R. K. (1969). Looking at upside-down faces. J. Exp. Psychol. 81, 141-145.

Conflict of Interest Statement: The authors declare that the research was conducted in the absence of any commercial or financial relationships that could be construed as a potential conflict of interest.

Received: 06 April 2011; accepted: 19 May 2011; published online: 01 June 2011.

Citation: Gainotti G and Marra C (2011). Differential contribution of right and left temporo-occipital and anterior temporal lesions to face recognition disorders. Front. Hum. Neurosci. 5:55. doi: 10.3389/ fnhum.2011.00055

Copyright $\odot 2011$ Gainotti and Marra. This is an open-access article subject to a non-exclusive license between the authors and Frontiers Media SA, which permits use, distribution and reproduction in other forums, provided the original authors and source are credited and other Frontiers conditions are complied with. 